Pfizer Inc, A. Maniccia Shareholder of: Pfizer Inc, Employee of: Pfizer Inc, L. Wang Shareholder of: Pfizer Inc, Employee of: Pfizer Inc, E. Akylbekova Consultant for: Pfizer Inc, Employee of: IQVIA, G. Ackermann Employee of: Pfizer AG, J. von Kempis: None declared

DOI: 10.1136/annrheumdis-2018-eular.3110

\section{OP0034 LONG-TERM EFFECTIVENESS OF THE COBRA SLIM REMISSION INDUCTION AND TREAT TO TARGET STRATEGY IN PATIENTS WITH EARLY RHEUMATOID ARTHRITIS LACKING CLASSICAL MARKERS OF POOR PROGNOSIS: 2 YEAR RESULTS OF THE CARERA TRIAL}

V. Stouten ${ }^{1}$, J. Joly ${ }^{2}$, S. Pazmino ${ }^{1}$, K. Van der Elst ${ }^{1,2}$, D. De Cock ${ }^{1}$, R. Westhovens ${ }^{1,2}, P$. Verschueren ${ }^{1,2}$, on behalf of the CareRA study group. ${ }^{1}$ Skeletal Biology and Engineering Research Centre, KU Leuven; ${ }^{2}$ Rheumatology, University Hospitals Leuven, Belgium

Background: EULAR guidelines recommend to treat all patients with early Rheumatoid Arthritis (eRA) with a combination of methotrexate (MTX) and a short-term course of Glucocorticoids (GC). The COBRA Slim strategy with MTX and a moderately dosed tapering down scheme of GC was effective, also in patients without classical markers of poor prognosis during the first year.

Objectives: To compare the outcomes of MTX with or without initial step-down GC in Low-Risk patients during the second year of the CareRA trial, in terms of disease control, safety and DMARD use.

Methods: CareRA is a two-year prospective investigator-initiated pragmatic multicentre RCT. DMARD naïve eRA patients were stratified into a High- or Low-Risk group based on classical prognostic markers (presence of erosions, RF, anti-CCP and DAS28-CRP). Low-Risk patients $(n=90)$ were randomised to either TightStep Up (TSU) with MTX $15 \mathrm{mg}$ weekly without GC or to COBRA Slim, a combination of MTX $15 \mathrm{mg}$ weekly and prednisone tapering down scheme starting at $30 \mathrm{mg}$, tapered to $5 \mathrm{mg}$ daily from w6 and stopped at w34. A treat-to-target approach was applied until year 1 and afterwards treatment was at the discretion of the rheumatologist. Proportions of DAS28-CRP remission at year 2 was a coprimary CareRA endpoint. Secondary outcomes were efficacy according to other remission criteria, EULAR/ACR response rates and functionality measured by HAQ (ITT analysis, last observation carried forward). Adverse events (AEs) and concomitant medication were registered.

Results: At year 2, $67.4 \%$ of Slim and $70.2 \%$ of TSU patients were in remission according to DAS28CRP ( $p=0.777$ ). Out of patients in DAS28CRP remission at year $1,80.0 \%(24 / 30)$ in the Slim group, versus $69.0 \%(20 / 29)$ in the TSU group remained in remission at every three-monthly evaluation until year 2 . Remission rates defined by Boolean criteria were higher in patients of the Slim (39.5\%) versus TSU group (19.1\%) ( $p=0.033)$. Functionality measured by mean area under the HAQ curve over 2 years was better in Slim patients (38.3 \pm 47.2$)$ than in TSU patients $(56.4 \pm 48.7)(p=0.025)$. Other secondary efficacy outcomes did not differ

Abstract OP0034 - Table 1 Clinical outcomes during the second year per treatment arm

\begin{tabular}{|l|c|c|c|}
\cline { 2 - 4 } \multicolumn{1}{c|}{} & $\begin{array}{c}\text { COBRA slim } \\
(\mathbf{n}=\mathbf{4 3})\end{array}$ & $\begin{array}{c}\text { TSU } \\
(\mathbf{n}=\mathbf{4 7})\end{array}$ & p-value \\
\hline Remission DAS28-CRP year 2 & $29(67.4 \%)$ & $33(70.2 \%)$ & 0.777 \\
\hline DAS28-CRP change BL-year 2 & $2.2 \pm 1.8$ & $2.2 \pm 2.0$ & 0.929 \\
\hline DAS28-CRP change year 1-year 2 & $0.1 \pm 0.8$ & $0.0 \pm 0.9$ & 0.486 \\
\hline Mean AUC of DAS28CRP & $248.9 \pm 110.8$ & $266.1 \pm 82.3$ & 0.119 \\
\hline Good EULAR response at year 2 & $55.8 \%$ & $61.7 \%$ & 0.571 \\
\hline ACR50 improvement at year 2 & $25(58.1 \%)$ & $23(48.9 \%)$ & 0.382 \\
\hline ACR70 improvement at year 2 & $19(44.2 \%)$ & $15(31.9 \%)$ & 0.230 \\
\hline Remission CDAl year 2 & $20(46.5 \%)$ & $15(31.9 \%)$ & 0.156 \\
\hline Remission SDAI year 2 & $20(46.5 \%)$ & $15(31.9 \%)$ & 0.156 \\
\hline Remission Boolean year 2 & $\mathbf{1 7}(39.5 \%)$ & $\mathbf{9 ( 1 9 . 1 \% )}$ & $\mathbf{0 . 0 3 3}$ \\
\hline Mean AUC of HAQ & $\mathbf{3 8 . 3 \pm 4 7 . 2}$ & $\mathbf{5 6 . 4 \pm 4 8 . 7}$ & $\mathbf{0 . 0 2 5}$ \\
\hline Clinically meaningful HAQ change at year 2 & $53.5 \%$ & $59.6 \%$ & 0.561 \\
\hline HAQ = 0 at year 2 & $48.8 \%$ & $36.2 \%$ & 0.224 \\
\hline
\end{tabular}

DAS28-CRP $=28$ Joint disease activity score calculated with C-reactive protein; good EULAR response $=$ low disease activity with a DAS28-CRPchange $(B L-y e a r 2)>1.2 ; A U C=$ Area Under the Curve (BL-year 2); $\mathrm{HAQ}=$ health assessment questionnaire; clinically meaning ful $\mathrm{HAQ}$ change (BL-year 2$)=$ HAQ change $>0.22$. between the treatment arms. The total numbers of AEs reported as related to study therapy, were 69 in 34 TSU patients and 63 in 28 Slim patients. Biologicals were started in 14 Low-Risk patients (15.6\%), more specifically in 8 Slim and 6 TSU patients during the CareRA trial. At the year 2 visit $62.5 \%$ of Slim patients were on MTX monotherapy and $12.5 \%$ on a combination of csDMARDs. In the TSU group $58.5 \%$ was taking MTX as only DMARD, and $19.5 \%$ took a combination of csDMARDs. Out of all Low-Risk patients $11.0 \%$ (8/73) was taking oral GC at the year 2 visit, 5 patients in the TSU group and 3 patients in Slim group, all at a low dosages.

Conclusions: In eRA patients lacking classical markers of poor prognosis COBRA Slim showed persistently high remission rates and good disease control 2 years after initiating therapy in a treat to target setting. COBRA slim seems to be slightly more effective than TSU according to the year 2 Boolean remission criteria and the 2 year functionality AUC but the CareRA study was not powered for this analysis.

Disclosure of Interest: V. Stouten: None declared, J. Joly: None declared, S Pazmino: None declared, K. Van der Elst: None declared, D. De Cock: None declared, R. Westhovens: None declared, P. Verschueren Grant/research support from: unrestricted Pfizer chair for management of early RA DOI: 10.1136/annrheumdis-2018-eular.2535

\section{OP0035 UPADACITINIB AS MONOTHERAPY: A PHASE 3 RANDOMISED CONTROLLED DOUBLE-BLIND STUDY IN PATIENTS WITH ACTIVE RHEUMATOID ARTHRITIS AND INADEQUATE RESPONSE TO METHOTREXATE}



A. Friedman ${ }^{6}$, A. Othman ${ }^{6}$, H. Camp ${ }^{6}$, A. Pangan ${ }^{6} .{ }^{1}$ Med Univ of Vienna, Vienna,

Austria; ${ }^{2}$ Metroplex Clin Res Ctr, Dallas, USA; ${ }^{3}$ Leeds Inst of Rheum and

Musculoskeletal Med, Leeds NIHR BRC, UK, Leeds, UK; ${ }^{4}$ Dartmouth Coll,

Hanover, USA; ${ }^{5}$ Univ of Occ and Env Health, Kitakyushu, Japan; ${ }^{6}$ AbbVie, $N$

Chicago, USA

Background: Upadacitinib (UPA), an oral JAK inhibitor, showed efficacy in rheumatoid arthritis (RA) patients (pts) with an inadequate response to csDMARDs or bDMARDs on continuing stable csDMARD(s). ${ }^{12}$

Objectives: Safety and efficacy of switching to UPA $15 \mathrm{mg}$ or $30 \mathrm{mg}$ monotherapy vs continuing methotrexate (MTX) as a blinded study drug was evaluated in pts with inadequate response to MTX (MTX-IR).

Methods: Pts with active RA (TJC $\geq 6, \mathrm{SJC} \geq 6$, hsCRP $\geq 3 \mathrm{mg} / \mathrm{L}$ ) on stable MTX were enrolled and randomised 1:1:1 in a double-blind manner to once-daily (QD) UPA $15 \mathrm{mg}$ or $30 \mathrm{mg}$ monotherapy or to continue MTX (cMTX) at their prior stable dose. At BL, all pts discontinued prior MTX without washout and received PBO (for pts on UPA) or MTX at prior dose (cMTX) as blinded study drug. The primary endpoints at Week (Wk) 14 were the proportion of pts achieving ACR20, and the proportion achieving DAS28-CRP $\leq 3.2$ (NRI)

Results: 648 pts were randomised, all received study drug; 598 (92.3\%) completed 14 wks. BL demographics and disease characteristics were generally similar across arms. Both primary endpoints were met $(p<0.001)$; at Wk 14 , a significantly greater proportion of pts receiving UPA monotherapy (15 mg and $30 \mathrm{mg})$ vs cMTX achieved ACR20 (67.7\% and $71.2 \%$ vs $41.2 \%)$, and DAS28CRP $\leq 3.2$ (44.7\% and $53.0 \%$ vs $19.4 \%$ ) (table 1 ). All key secondary endpoints also showed UPA 15 and UPA 30 monotherapy to be superior to CMTX, including ACR50 (41.9\% and $52.1 \%$ vs $15.3 \%$ ), ACR70 (22.6\% and $33.0 \%$ vs $2.8 \%$ ) DAS28-CRP $<2.6$ (28.1\% and $40.5 \%$ vs $8.3 \%), \Delta \mathrm{HAQ}-\mathrm{DI}(-0.65$ and -0.73 vs -0.32). $\triangle$ SF-36 PCS and $\triangle$ Morning Stiffness data are also shown (table 1). The proportion of pts achieving CDAI $\leq 10$ was significantly greater with UPA 15 and 30 vs cMTX (34.6\% and $46.5 \%$ vs $24.5 \%$ ).

Adverse events (AEs) were reported at similar frequencies across arms; serious AEs were numerically higher in UPA 15 but similar between CMTX and UPA 30 (table 1). Numerically more infections were reported in CMTX and UPA 30 vs UPA 15. One serious infection each was reported in UPA 15 and CMTX, and none in UPA 30. Herpes zoster was more frequent in UPA 30 vs UPA 15 or cMTX. 3 malig nancies ( 1 in cMTX and 2 in UPA 15) and 3 adjudicated MACE ( 1 in UPA 15 and 2 in UPA 30 ) were reported. One adjudicated pulmonary embolism was reported (UPA 15) in a pt with known risk factors (BMI 36; on oestrogen therapy). One death (haemorrhagic stroke due to ruptured aneurysm) was reported in UPA 15. No TB, renal dysfunction or GI perforation was reported. Rates and types of laboratory abnormalities were consistent with prior UPA RA studies to date. 